\title{
In vitro interaction of antimicrobial agents in combination with plant extract against multidrug-resistant bacterial strains
}

\author{
Muhammad Saqib Ishaq ${ }^{1}$, Abdur Razaq ${ }^{1}$, Muhammad Medrar Hussain ${ }^{1}$, Ghadir Ali ${ }^{1}$, Mahrukh Khattak ${ }^{2}$ and \\ Muhammad Amin ${ }^{1}$
}

\begin{abstract}
${ }^{1}$ Department of Microbiology, Faculty of Life sciences, Abasyn University, Peshawar 25000 Pakistan.
${ }^{2}$ Department of Microbiology, Shaheed Benazir Bhutto Women University, Peshawar 25000 Pakistan. Email: saqib.ishaq@abasyn.edu.pk
\end{abstract}

Received 8 July 2014; Received in revised form 28 March 2015; Accepted 22 April 2015

\begin{abstract}
Aims: To evaluate the possible in vitro interaction between methanolic extract of root of Adiantumcapillus-veneris and certain known antimicrobial drugs i.e. Oxacillin, Ceftazimide, Cefriaxone, Ofloxacin, Meropenem, Erythromycin, Cefuroxime, Cefoxitin, Cefotaxime and Ampicillin.

Methodology and results: The study was carried out against ten bacterial strains (Staphylococcus aureus, S. epidermidis, Salmonella typhi, Klebsiella pneumoniea, Shigella dysentriea, Proteus vulgaris, Pseudomonas aeruginosa, Providencia species, Citrobacter freundii and Escherichia coli isolated from urine, pus and blood samples. Both disc diffusion and well diffusion methods were used to determine antimicrobial activity of plant extract in combination with antibiotics. Antimicrobial sensitivity showed that Meropenem was the most effective antibiotic with zone of inhibition (ZI) of 25-33 mm among all tested antibiotics followed by Ofloxacin (10-26.5 mm), Ceftriaxone (8-20 mm), while Oxacillin showed no activity against almost all bacterial strains. The study showed that most bacterial strains were resistant to most of the antibiotics used, ranging from 20-60\%. The methanolic extract (mEXT) of $A$. capillus-veneris used alone was active against most of the bacterial isolates with maximum activity against $E$. coli with $16 \mathrm{~mm} Z$. The study also indicated that there was an increased activity in case of combination of mEXT with antibiotics. The combined effects of plant extract with antibiotics were synergistic against most of the bacterial strains. The mEXT showed maximum synergistic effect with Ceftazimide with ZI of $42 \mathrm{~mm}$ followed by Meropenem $(40 \mathrm{~mm})$ and Ceftriaxone $(28 \mathrm{~mm})$ against multidrug-resistant (MDR) bacterial strains.

Conclusion, significance and impact of study: The data suggests that plant extract could be used as alternative to antibiotics. These results give scientific backing that combination between plant extract and antibiotics would be useful in fighting the emerging drug-resistant bacterial pathogens.
\end{abstract}

Keywords: Adiantumcapillus-veneris, antibacterial activity, synergistic effects, antagonistic effect, medicinal plant

\section{INTRODUCTION}

Antibiotic resistant bacteria have been a source of ever increasing therapeutic problems (Sheikh et al., 2003). Continued mismanagement and indiscriminate usage of commonly prescribed antibiotics result in the emergence of MDR bacteria (Cohen, 1992). Antibiotics resistant bacteria can be found in all different ecological niches. Selective pressure of misuse of antibiotics mainly in hospitals, agriculture and animal farming, goes in favor of bacteria by developing new genes responsible for the antibiotic resistance (Kummerer, 2004). Liquid manure of animals as well as human excretion has also led to dissemination of resistant bacteria in the environment (Reinthaler, 2003).

\section{${ }^{\star}$ Corresponding author}

The emergence and spread of microbes that is resistant to cheap and effective first choice antibiotics has become a common occurrence. Face with this problem, there is a continuous and urgent need to discover new antimicrobial compounds with diverse chemical structure and novel mechanisms of action because there has been an alarming increase in the incidence of new and reemerging infectious diseases, appearance of undesirable side effects of certain antibiotics, as well as the increasing development of resistant to the antibiotics in current clinical use (Cowan, 1999). Therefore actions must be taken to control the use of antibiotics, to better understand the genetic mechanisms of resistance and to continue studies to develop new drugs.

There are different approaches to cure and control the infections caused by MDR bacterial strains. One of which 
is by isolation of active phytochemicals that can help to prevent the spread of infection. Another method is to formulate new synergistic combination using different commercially available antibiotics, or to combine an antibiotic with active phytochemicals having antimicrobial properties. It has been found that some medicinal plants produce MDR inhibitors which enhance the activities of antibiotics against MDR bacterial strains (Stermitz et al., 2000).

Several in vitro studies have reported synergistic effects resulting from the combination of different antibiotics with different plants extracts against MDR bacterial strains (Betoni et al., 2006). According to Estimone et al. (2006) the herb-drug interaction between tea extract and penicillin $\mathrm{G}$ against Staphylococcus aureus showed that the interaction was mainly additive. Sibanda and Ocoh (2008) showed potential of synergy between acetone extracts of Garcinia kola and Amoxicillin, Ciprofloxacin, Tetracycline and Chloramphenicol against MDR pathogenic microorganisms.

Adiantum capillus-veneris is commonly known as maiden hair fern belonging from kingdom Plantae and family Adiantaceae, distributed throughout the world and in different areas of Pakistan. It is traditionally used to treat infectious diseases (Singh et al., 2008). It can be used as expectorant, diuretic, as hair tonic and in chest disease (Piyali et al., 2005). It have various phytochemicals constituent like alkaloids, tannins, steroids, flavonoids, saponins, terpenoids, cardiac glycosides and reducing sugar, and also have antibacterial and antifungal activity (Ishaq et al., 2014).

Adiantum capillus-veneris has many traditional uses globally. It is used for blood cleaning, cough, menstrual and respiratory problems in Arizona. In Brazil it is used for asthma, bronchitis, cough, digestion, excessive mucous, flu and hair loss. Likewise, in India, it is used for asthma, boils, bronchial disease and cold diabetes (Ansari and Ekhlasi, 2012).

Therefore the present study was designed to investigate the antibacterial activity of methanolic extract of $A$. capillus-veneris and their interaction with ten commonly used antibiotics against MDR bacterial strains isolated from clinical samples.

\section{MATERIALS AND METHODS}

\section{Plant material collection and extraction}

The A. capillus-veneris was collected from different areas of Northern Pakistan and Swat. The plant was identified in the department of Botany, University of Peshawar, while processed in microbiology laboratory of Abasyn University Peshawar. The roots of $A$. capillus-veneris are used as plant sample for extract preparation which were first thoroughly washed with water and soaked in detergent to remove the microbial load on the surface of plant sample. These were then shade dried and ground to homogenous powder (Sood and Sharma, 2010). One hundred gram of powder was soaked in flask containing 1 liter methanol for $24 \mathrm{~h}$ at $25^{\circ} \mathrm{C}$ and then filtered through Whatman No. 1 filter paper (Cseke et al., 2006). The filtrate was collected in separate flask and the same process was repeated for three times. The filtrates, that is, crude extract obtained was concentrated in rotary evaporator. For the isolation of pure extract, the isolated crude extract was resuspended in a minimum required volume of corresponding solvent and placed on the water bath $\left(60^{\circ} \mathrm{C}\right)$ for the evaporation of extra solvents. The extract was then preserved in separate containers for further experimentations at $5{ }^{\circ} \mathrm{C}$, according to previous method of Deveeka et al. (2013).

\section{Collection and identification of bacterial strains}

Ten different bacterial strains used in this study were isolated from different clinical samples like urine, wound pus, and blood which were collected from the main laboratory of Khyber Teaching Hospital Peshawar, Pakistan. The isolated bacterial strains were sub-cultured on differential and selective media e.g. MacConkey, SS agar, MSA and CLED agar and were identified their specific morphological and biochemical characteristics (Collee and Marr, 1996).

\section{Assessment of drug resistance pattern of test bacterial strains}

The Kirby-Baur method described by Benson (2002) was used to study antimicrobial sensitivity tests. Disc diffusion method was used for measurement of the antimicrobial activity of antibiotic discs on Mueller-Hinton agar. The organisms were tested against ten commonly used antibiotics. Antibiotics used were Oxacillin (OX) $(1 \mu \mathrm{g})$, Ceftazimide (CAZ) $(30 \mu \mathrm{g})$, Cefotaxime (CTX) $(30 \mu \mathrm{g})$, Ceftriaxone (CRO) $(30 \mu \mathrm{g})$, Cefuroxime (CXM) $(30 \mu \mathrm{g})$, Meropenem (MEM) (10 $\mu \mathrm{g})$, Oflaxacin (OFX) (5 $\mu \mathrm{g})$, Cefoxitin (FOX) $(30 \mu \mathrm{g})$, Ampicillin (AMP) $(10 \mu \mathrm{g})$ and Erythromycin $(E)(15 \mu \mathrm{g})$ and the process was repeated thrice. All the plates were incubated at $37^{\circ} \mathrm{C}$ for $24 \mathrm{~h}$.

\section{Antimicrobial activity of plant extract}

Well diffusion method of Janovska et al. (2003) was followed with some modifications for the antimicrobial activity of plant extracts. One $\mathrm{mg}$ of plant extract was dissolved in $1 \mathrm{~mL}$ of dimethyl sulfoxide (DMSO) $(1 \mathrm{mg} / 1$ $\mathrm{mL}$ ). Pre-autoclaved Nutrient agar plates were inoculated with a $10^{-5}$ dilution of bacterial culture, using sterile cotton swabs to achieve uniform lawn of growth and sterile cork borer was used to bore wells in the agar. Sixty microliters of extract was introduced through micropipette aseptically into specifically marked wells in the agar plates. All cultured plates were incubated at $37^{\circ} \mathrm{C}$ for $24 \mathrm{~h}$ and the process was repeated thrice.

\section{Combined plant extract and antibiotics}

The combine activity of plant extract and antibiotics was calculated by combining different antibiotics and extract using agar well method. The plates were incubated for 24 $\mathrm{h}$ at $37^{\circ} \mathrm{C}$ and synergistic and antagonistic effects were 
measured and compared with individually used extract and antibiotics (Okore, 2009).

\section{RESULTS}

\section{Drug resistance profile of the test bacterial strains}

Different bacterial species were isolated from different sources like $S$. aureus and Salmonella typhi were isolated from blood samples, Escherichia coli, Klebsiella pneomoniiae, Citrobacter freundii, Shigella dysentriae, Proteus vulgaris and Providencia species from urine while Pseudomonas aeruginosa and Staphylococcus epidermidis were isolated from wound pus. The bacterial strains were tested for antibiotics sensitivity profile against 10 frequently used antibiotics. Most of the tested bacterial strains were found to be resistant to the used antibiotics. $E$. coli and $S$. typhi were found to be the most resistant bacterial strains $(60 \%)$ to all tested antibiotics, followed by S. dysentriae, K. pneumoiae and Providencia (50\%), S. aureas and $P$. aeruginosa (40\%), C. freundii (30\%), $S$. epidermidis and $P$. vulgaris (Figure 1 ).

Table 1: Drug resistance profile of test bacterial strains.

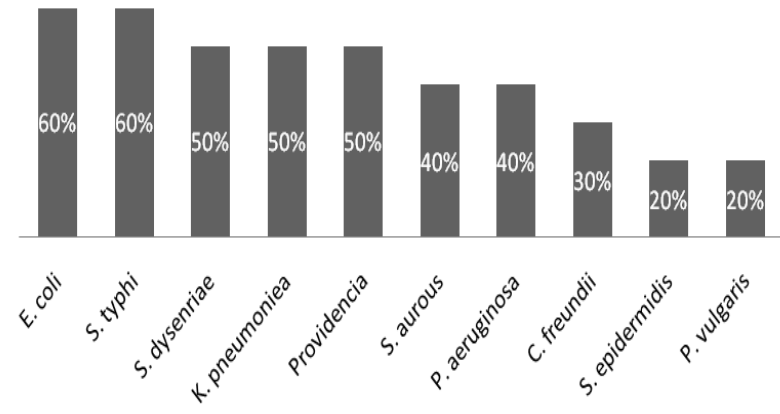

Figure 1: Percentage of antibiotic sensitivity of MDR bacterial strains.

Amongst all used antibiotics MEM showed maximum effect against all tested bacterial strains. The maximum $\mathrm{ZI}$ was shown by Providencia species and $P$. aeroginosa (34 $\mathrm{mm})$ followed by $E$. coli and $S$. dysentriea $(33 \mathrm{~mm}), P$. vulgaris $(32.5 \mathrm{~mm}), C$. freundii $(32 \mathrm{~mm}), S$. aureus and $S$. epidermidis $(31 \mathrm{~mm}), S$. typhi $(30 \mathrm{~mm})$, and $K$. pneumoniae $(25 \mathrm{~mm})$. The most effective antibiotics were OFX, CTX and CRO (Figure 1 and Table 1).

\begin{tabular}{|c|c|c|c|c|c|c|c|c|c|c|}
\hline \multirow{3}{*}{ Microorganisms } & \multicolumn{10}{|c|}{ Antibiotics disc with ZI (mm), while (--) representing resistance } \\
\hline & 1 & 2 & 3 & 4 & 5 & 6 & 7 & 8 & 9 & 10 \\
\hline & OX & CAZ & CTX & CXM & MEM & FOX & OFX & AMP & $\mathrm{E}$ & $\mathrm{CRO}$ \\
\hline E. coli & -- & -- & 18 & -- & 33 & 20.5 & -- & -- & -- & 17.5 \\
\hline S. epidermidis & -- & -- & 18 & 12 & 31 & 26.5 & 18 & 12.5 & 22 & 15.5 \\
\hline S. dysentriae & -- & 22 & 17 & -- & 33 & 23 & -- & -- & -- & 18 \\
\hline S. typhi & -- & -- & 13 & -- & 30.5 & 18.5 & -- & -- & -- & 8 \\
\hline P. vulgaris & -- & -- & 19 & 15 & 31.5 & 30 & 18.5 & 14 & 25 & 19 \\
\hline Providencia & -- & 17 & 16 & -- & 34 & 10 & -- & -- & -- & 20 \\
\hline S. aureus & -- & 24 & 14.5 & -- & 31 & 20 & -- & 8 & -- & 15 \\
\hline$P$. aeruginosa & -- & 14 & 15 & -- & 34 & 19.5 & 12 & -- & -- & 20 \\
\hline K. pneomoniea & -- & 10 & -- & -- & 25 & 20 & 11 & -- & 8 & -- \\
\hline C. fruendii & -- & 28 & 18 & -- & 32 & 18 & -- & -- & -- & 18 \\
\hline
\end{tabular}

Table 2: Antibacterial activity of plant extract.

\begin{tabular}{cc}
\hline Microorganisms & $\begin{array}{c}\text { Antibacterial activity of extract of } \\
\text { Adiantum capillus-veneris against MDR bacterial } \\
\text { strains }\end{array}$ \\
\hline E. coli & 16 \\
S. epidermidis & 12 \\
S. dysentriea & 10 \\
S. typhi & 0 \\
P. vulgaris & 0 \\
Providencia species & 8 \\
S. aureus & 10 \\
P. aeruginosa & 7 \\
K. pneumonia & 0 \\
C. freundii & 11 \\
\hline Extracts with zone of inhibition (ZI) representing sensitivity in millimeter (mm)
\end{tabular}




\section{Assessment of antibacterial activity of plant extract}

The extracts of Adiantum capillus veneris showed little effect against tested bacterial strains. The extract showed maximum $\mathrm{Zl}$ against $E$. coli $(16 \mathrm{~mm})$, followed by $S$. epidemidis and $C$. freundii $(12 \mathrm{~mm}), S$. dysentriea and $S$. aureas $(10 \mathrm{~mm})$, Providencia species $(8 \mathrm{~mm}), P$. aeruginosa $(7 \mathrm{~mm})$, while showed resistance to $S$. typhi, $P$. vulgaris and K. pneumoniae (Table 2 ).

\section{Combined effect of plant extract with antibiotics}

The combined effects of plant extract with antibiotics were different from individually used antibiotics and extract of Adiantum capillus-veneris. The maximum antibiotics showed synergistic effects, some were antagonistic while some of them showed neither synergistic nor antagonistic effects against test MDR bacterial strain. CXM combined with mEXT showed synergistic effects against most of the bacterial strain. Its Maximum $\mathrm{ZI}$ was against $P$. vulgaris $(30 \mathrm{~mm}), S$. aurous $(17 \mathrm{~mm}), P$. auruginosa and $S$. epidermidis (16 mm), $S$. dysentriae $(15 \mathrm{~mm}), S$. typhi and Providencia species $(10 \mathrm{~mm})$, while there were no significant effects against $K$. pneumonia and $C$. freundii. Another antibiotic CTX showed good effect in combination with plant extract against all tested organisms. The maximum combined $\mathrm{ZI}$ of CTX with plant extract was observed against $S$. aureus $(25 \mathrm{~mm})$, followed by $E$. coli and $P$. auroginosa $(22 \mathrm{~mm}), S$. dysentriae and $S$. epidermidis $(21 \mathrm{~mm})$ Providensia species and $C$. frundii $(18 \mathrm{~mm}) S$. typhi and $P$. vulgaris $(17 \mathrm{~mm})$ and $K$. pneumoniae $(15 \mathrm{~mm})$. Other antibiotics that were used in combination with mEXT are shown in Table 3.

Table 3: Combined activities of antibiotics with methanolic extract of $A$. capillus-veneris.

\begin{tabular}{|c|c|c|c|c|c|c|c|c|c|c|}
\hline \multirow{3}{*}{ Microorganisms } & \multicolumn{10}{|c|}{ Combined $\mathrm{ZI}$ in $(\mathrm{mm})$ of plant extract with antibiotics } \\
\hline & 1 & 2 & 3 & 4 & 5 & 6 & 7 & 8 & 9 & 10 \\
\hline & OX & CAZ & CTX & CXM & MEM & FOX & OFX & AMP & $\mathrm{E}$ & $\mathrm{CRO}$ \\
\hline E. coli & $12 s$ & - -i & $22 s$ & $23 \mathrm{~s}$ & $38 \mathrm{~s}$ & $21 \mathrm{~s}$ & $-\mathrm{i}$ & $8 s$ & $--i$ & $20 \mathrm{~s}$ \\
\hline S. epidermidis & $15 s$ & $20 \mathrm{~s}$ & $21 s$ & $16 s$ & $40 s$ & $24 a$ & 22 & ND & ND & $22 s$ \\
\hline S. dysentriea & $--i$ & $26 s$ & $20 s$ & $15 s$ & $38 s$ & $25 s$ & ND & ND & ND & $22 s$ \\
\hline S. typhi & $--i$ & $42 s$ & $17 s$ & $10 \mathrm{~s}$ & $35 s$ & $23 s$ & ND & ND & ND & $28 s$ \\
\hline P. vulgaris & $--i$ & $32 s$ & $17 a$ & $30 \mathrm{~s}$ & $40 s$ & $--a$ & $30 \mathrm{~s}$ & $16 s$ & $25 \mathrm{~s}$ & $20 \mathrm{~s}$ \\
\hline Providencia & $--i$ & $22 s$ & $18 s$ & $10 \mathrm{~s}$ & $35 s$ & $18 \mathrm{~s}$ & $35 \mathrm{~s}$ & ND & ND & $23 \mathrm{~s}$ \\
\hline S. aureus & $14 s$ & $31 \mathrm{~s}$ & $25 s$ & $17 \mathrm{~s}$ & $40 s$ & $25 s$ & ND & ND & ND & $24 s$ \\
\hline P. aeruginosa & $--i$ & $20 s$ & $22 s$ & $16 s$ & $40 s$ & $16 a$ & $20 s$ & ND & ND & $22 s$ \\
\hline K. pneomoniea & $--i$ & $--i$ & $15 s$ & $--\mathrm{i}$ & $33 s$ & $16 \mathrm{a}$ & $18 \mathrm{~s}$ & ND & ND & $20 s$ \\
\hline C. fruendii & $--i$ & $32 s$ & $18 s$ & - -i & $35 s$ & $15 s$ & ND & ND & ND & $25 s$ \\
\hline
\end{tabular}

\section{DISCUSSION}

The outgoing emergence of antibiotic resistance has diverted the attention of researchers towards the medicinal plants and search of new and effective drugs. In this connection, Yang et al. (2010) stated that, in recent years, human pathogenic microorganisms have developed multiple drug resistance and causing nosocomial infections. Moreover, it was suggested that plant extracts can be further developed into antibiotic medicine due to their proven antimicrobial activity.

The present study has shown that methanolic extract of roots of $A$. capillus-veneris in combination with antibiotics inhibited the growth of test MDR bacterial strains at high level than were tested separately. This effect was synergistic or additive for the most of the test bacterial strains. Synergistic and additive interactions are a result of a combined effect of active compounds from plant extract and antibiotics. The plant extracts contain a great number of different compounds (phenol. flavonoids, tannins, coumarins, alkaloids and terpenoids) which have an impact on growth and metabolism of microorganisms (Cowan, 1999).

In the present study 10 bacterial strains were used which were multidrug-resistant to most of the given antibiotics. The results showed that E. coli and S. typhi were the most resistant strains (60\%) among all the tested bacterial strains. This result goes in line with the studies in other countries of the world where $95-100 \%$ MDR E. coli was reported (Dimah, 2012). Moreover, (67\%) MDR E. coli was seen in the study of Ogunleye et al.(2008). In India 10\% MDR S. typhi was reported (Nagshetty et al., 2010). Similarly 50\% MDR Providencia species evaluated in our study is almost in line with the study of Tumbarello et al. (2004) who reported 75\% MDR Providencia species. We have also investigated that $S$. disentriae, $S$. aureus, $P$. aeroginosa, $C$. freundii, $S$. epidermidis and $P$. vulgaris are rather more MDR than what was found in other regions of the world. 
Several studies on $A$. capillus-veneris revealed its potency against MDR bacterial strains. For example $E$. coli, S. epidermidis, S. dysnertriae, Providencia species, $P$. aeroginosa and $C$. freundii were sensitive to methanolic extract of root of $A$. capillus-veneris, while K. pneumonia, $S$. typhi and $P$. vulgaris were resistant. This study proved to be almost in accordance with the finding of Kumar and Nagarjan (2012) and Mahboubi et al. (2012).

Our result revealed that the combination of plant extracts and antibiotics could be useful in treatment of infectious diseases and useful in fighting emerging drug resistance problems. Synergistic effect was more pronounced in case of all the strains as evident from zone of inhibition of all the strains presented in Table 3. In all cases more than $15 \%$ increase in $\mathrm{ZI}$ was observed which is highly significant different.

Several studies evaluated the interactions of plants extract and certain antimicrobial agents and their impacts on MDR bacterial strains. Tiwari et al. (2005) reported that Chloramphenicol and Tea extract in combination inhibited the growth of $S$. dysentriae, tea extract showed synergistic activity with Chloramphenicol and other antibiotics like Gentamycin, Methicillin and Nalidixic acid against tested bacterial strains. Voukeng et al. (2012) indicated that plant extracts contain chemicals that can modulate the activity of antibiotics against bacteria expressing MDR phenotypes.

Comparing with all these studies, the study concluded that the extract of roots of $A$. capillus-veneris have bioactive compounds that enhances the antimicrobial activities of antibiotics that have shown no effect or little effect against MDR bacterial strains.

\section{ACKNOWLEDGMENTS}

The authors thank Mr. Muhammad Imranullah Chancellor and Mr. Muhammad Irfanullah Director of Abasyn University Peshawar, Pakistan for providing excellent research facilities and financial support in the form of research project.

\section{REFERENCES}

Ansari, R. and K. Ekhlasi-Kazaj, K. (2012).Adiantum capillus-veneris L: Phytochemical constituents, traditional uses and pharmacological properties: A review. Journal of Advanced Scientific Research 3(4), 15-20.

Benson, J. H. (2002). Microbiological applications: Laboratory manual in general microbiology. McGraw Hill. Boston, MA, pp.168-175.

Betoni, J. E., Mantovani., R. P., Barbosa., L. N., Di Stasi, L. C. and Junior, A. F. (2006). Synergistic between plant extract and antimicrobial drugs used on Staphylococcus aureus diseases. Memorias do instituto oswaldo Cruz101(4), 387-390.

Cohen, M. L. and Auxe, R. V. (1992). Drug resistant Salmonella in the United States: An epidemiologic perspective. Science 234, 964-970.
Collee, J. G. and Marr, W. (1996). Specimen collection, culture containers and media. In: Mackie \& McCartney Practical Medical Microbiology. Collee, J. G., Fraser, A. G., Marmion, B. P., Simmons, A.(eds.). 14th edn. Churchill Livingstone, New York.pp.85-111.

Cowan, M. M. (1999). Synergistic and additive interaction of $S$. officinalis extract and some antibiotics. Clinical Microbiology Reviews 12, 564-570.

Cseke, L. J., Kirakosyan. A., Kaufaman, P. B., Warber. S. L., Duke, J. A. and Brielmann, H. L. (2006). Natural products from plants CRC Press. USA.

Deveeka, K. Z., Baburao, K. and Samal, K. C. (2013). In vitro antibacterial and synergistic effect of plant extracts and synthetic antibiotic (Aztreonam) against extended bacterial spectrum. International Journal of Agriculture, Environment and Biotechnology 6(4), 591598.

Dimah, N. P. (2012). Interaction of black and green tea water extracts with antibiotic activity in local urinary isolated Escherichia coli. Journal of al-Nahrain University 15(3), 134-142.

Estimone, C. O., Iroha, I. R. Ibezim, E. C. Okeh, C. O. and Okpana, E. M. (2006). Evaluation of herb-drug interaction between tea extract and Pencillin $\mathrm{G}$ against Staphylococcus aureus. African Journal of Biotechnology 5, 76-82.

Ishaq, M. S., Hussain, M. M. Afridi, M. S., Ali, G., Khattak, M., Ahmad, S. and Shakirullah. (2014).In vitro phytochemical, antibacterial and antifungal activities of leaf, stem, and root extracts of Adiantum capillus veneris. The Scientific World Journal (http://dx.doi.org/10.1155/2014/269793).

Janovska, D., Kubikova, K. and Kokoska, L. (2003). Screening for antimicrobial activity of some medicinal plants species of traditional Chinese medicine. Czech Journal of Food Sciences 21, 107-110.

Kumar, S. S. and Nagarajan, N. (2012). Screening of preliminary phytochemical constituents and antimicrobial activity of Adiantum capillus veneris. Journal of Research in Antimicrobial 1(1), 56-61.

Kummerer, K. (2004).Resistance in the environment: $A$ review. Journal of Antimicrobial Chemotherapy 54(2), 311-320.

Mahboubi, A., Kamalinejad, M., Shalviri, M., Karbasi, Z., Jafariazar, Z. and Asgharian, R. (2012). Evaluation of antibacterial activity of three Iranian medicinal plants. African Journal of Microbiology 6(9), 2048-2052.

Nagshetty, K., Shivannavar., T. C. and Gaddad, S. M. (2010).Antimicrobial susceptibility of Salmonella Typhi in India. The Journal of Infection in Developing Countries 4(2), 70-73.

Ogunleye, A. O., Oyekunle, M. A. and Sonibare, A. O. (2008). Multidrug-resistant Escherichia coli isolates of poultry origin in Abeokuta, South Western Nigeria. Veterinarski Arhiv 78(6), 501-509.

Okore, V. T. (2009). Principle of pharmaceutical microbiology. Ephrata Publisher, Nigeria. 
Piyali, G. G., Mukhopadhyay, R. and Gupta, K. (2005). Antifungal activity of the crude extracts and extracted phenol from gametophytes and sporophytes of two species of Adiantum. Taiwania 50(4), 272-283.

Reinthaler, F. F., Posch, J., Feirel, G., Wust, G., Haas, D., Ruckenbauer, G., Mascher, F. and Marth, E. (2003). Antibiotic resistant of $E$. coli in sewage and sludge. Water Research 37, 1685-1690.

Sheikh, A. R., Afsheen, A., Sadia, K. and Abdul, W. (2003). Plasmid borne antibiotic resistance factors among indigenous Klebseilla. Pakistan Journal of Botany35(2), 243-248.

Sibanda, T. and Okoh, A. I. (2008). Interaction between plant extract and antibiotics on multidrug-resistant bacteria. African Journal of Microbiology 7(11), 16721978.

Singh, M., Singh, N., Khare, P. B. and Rawat, A. K. (2008). Antimicrobial activity of some important Adiantum species used traditionally in indigenous system of medicines. Journal of Ethnopharmocology 115(2), 327-329.

Sood, S. and Sharma, N. (2010). Insect growth regulatory activity of Adiantum capillus veneris against Plutella xylostella and Aphis craccivora in ethanol and methanol. Research Journal of Agriculture and Biological Science 6(6), 785-790.

Stermitz, F., Lorenz, P., Taawara, J. N., Zenewicz, L. A. and Lewis, K. (2000).Synergism in a medicinal plant: Antimicrobial action of berberine potentiated by S-methoxyhydrocarpin-a multidrug pump inhibitor. Proceedings of National Academy of Sciences 97(4), 1433-1437.

Tiwari, R. P., Bharti., S. K. Kaur, H. D. Dikshit, R. P. and Hoondal, G. S. (2005). Synergistic antimicrobial activity of tea and antibiotics. Indian Journal of Medical Research 122, 80-84.

Tumbarello, M., Citton, R.,Spano, T., Sanguinetti, M., Romano, L. G., Fadda, G. and Cauda, R. (2004). ESBL-producing multidrug-resistant Providencia stuartii infections in a university hospital. Journal of Antimicrobial Chemotherapy 53(2), 277-282.

Voukend, I. G., Kuete, V., Dzoyem, J. P., Fankam, A. G., Noumedem, J. A., Kuiate, J. R. and Pages, J. M. (2012). Antibacterial and antibiotic-potentiation activities of the methanol extract some cameroonian spices against Gram-negative multidrug-resistant phenotypes. BMC Research Notes 5, 299.

Yang, J., Yang, C. and Cahng, H. (2010). Chemical composition and antimicrobial activity of Licium against antibiotics resistant pathogens. Journal of Medicinal Food 13(5), 1254-1262. 